\title{
30 Minutes per Day for 5 Days a Week Over Next 24 Weeks
}

National Cancer Institute

\section{Source}

National Cancer Institute. 30 Minutes per Day for 5 Days a Week Over Next 24 Weeks. NCI Thesaurus. Code C122996.

A time period of 30 minutes per day for 5 days per week over the next 24 weeks. 